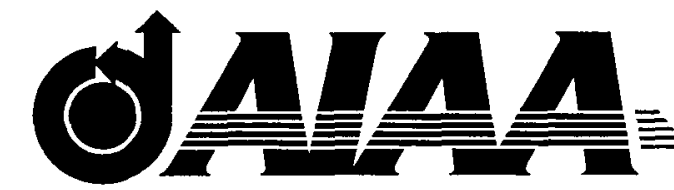

\title{
AIAA-2004-1315
}

\section{High-school student teams in a national NASA microgravity science competition}

Richard DeLombard and Dennis Stocker

NASA Glenn Research Center

Cleveland, Ohio

Carol Hodanbosi

National Center for Microgravity Research in Fluids and Combustion

Cleveland, Ohio

For permission to copy or to republish, contact the copyright owner named on the first page.

For AIAA-held copyright, write to AIAA Permissions Department,

1801 Alexander Bell Drive, Suite 500, Reston, VA, 20191-4344.

This is a preprint or reprint of a paper intended for presentation at a

conference. Because changes may be made before formal

publication, this is made available with the understanding that it will
not be cited or renrntirent withn it thn 


\section{HIGH-SCHOOL STUDENT TEAMS IN A NATIONAL NASA MICROGRAVITY SCIENCE COMPETITION}

\author{
Richard DeLombard \\ NASA Glenn Research Center \\ Cleveland, Ohio \\ Carol Hodanbosi \\ National Center for Microgravity Research \\ NASA Glenn Research Center \\ Cleveland, Ohio
}

\author{
Dennis Stocker \\ NASA Glenn Research Center \\ Cleveland, Ohio
}

\begin{abstract}
The Dropping In a Microgravity Environment or DIME competition for high-school-aged student teams has completed the first year for nationwide eligibility after two regional pilot years. With the expanded geographic participation and increased complexity of experiments, new lessons were learned by the DIME staff.

A team participating in DIME will research the field of microgravity, develop a hypothesis, and prepare a proposal for an experiment to be conducted in a NASA microgravity drop tower. A team of NASA scientists and engineers will select the top proposals and then the selected teams will design and build their experiment apparatus. When completed, team representatives will visit NASA Glenn in Cleveland, Ohio to operate their experiment in the 2.2 Second Drop Tower and participate in workshops and center tours.

NASA participates in a wide variety of educational activities including competitive events. There are competitive events sponsored by NASA (e.g. NASA Student Involvement Program) and student teams mentored by NASA centers (e.g. For Inspiration and Recognition of Science and Technology Robotics Competition). This participation by NASA in these public forums serves to bring the excitement of aerospace science to students and educators.
\end{abstract}

Researchers from academic institutions, NASA, and industry utilize the 2.2 Second Drop Tower at NASA Glenn Research Center in Cleveland, Ohio for microgravity research. The researcher may be able to complete the suite of experiments in the drop tower but many experiments are precursor experiments for spaceflight experiments. The short turnaround time for an experiment's operations (45 minutes) and ready access to experiment carriers makes the facility amenable for use in a student program.

The pilot year for DIME was conducted during the 2000-2001 school year with invitations sent out to Ohiobased schools and organizations. A second pilot year was conducted during the 2001-2002 school year for teams in the six-state region of Illinois, Indiana, Michigan, Minnesota, Ohio, and Wisconsin. The third year for DIME was conducted during the 2002-2003 school year for teams from the fifty United States, the District of Columbia, and Puerto Rico. An annual national DIME program is planned for the foreseeable future.

Presented in this paper will be a description of DIME, an overview of the planning and execution of such a program, results from the first three years, and lessons learned from the first national competition.

\section{ACRONYMS \& ABBREVIATIONS}

$1 \mathrm{~g}$

Earth's gravitational acceleration at sea-level, approximately $9.8 \mathrm{~m} / \mathrm{s}^{2}$

DIME Dropping In a Microgravity Environment

ITEA International Technology Education Association

NASA National Aeronautics and Space Administration

NCMR National Center for Microgravity Research in Fluids and Combustion

NSTA National Science Teachers Association 


\section{INTRODUCTION}

The NASA Administrator, Sean O'Keefe, stated in congressional testimony that NASA has made education a core mission of the Agency. (ref. 1)

Young people are full of wonder and discovery and NASA has a responsibility to help those traits mature. As we seek to improve our life here, and extend life beyond our known universe, we must work to inspire our children to explore the great frontiers of our solar system and conquer the challenges of propulsion, human biology and technology that keep us close to our home planet. That means we have to help our students understand how mathematics, science, engineering and technology come together to make exploration and innovation possible. Too many students avoid these subjects because they are seen as unpopular, not relevant to their daily lives, or too difficult. These very subject areas though are the fundamental baseline of NASA mission success.

The NASA John H. Glenn Research Center at Lewis Field has long been committed to educational outreach. A new educational activity was started in the school year 2000/01 that takes teams of students through a research process similar to processes used by NASA, academia, and commercial researchers. The Dropping In a Microgravity Environment (DIME) program involves student teams from the development of an experiment concept through building the experiment apparatus and conducting the experiment to obtain data which is analyzed and presented in a final report.

The Microgravity Science Division works jointly with the National Center for Microgravity Research in Fluids and Combustion (NCMR) located on-site at NASA Glenn. NCMR also manages the division's education outreach efforts and plays a major role in the DIME program.

\section{DROP TOWERS}

Microgravity conditions are created for experiments in a variety of facilities, such as the International Space Station, not by reducing gravity levels to zero, but by allowing an experiment to free fall within the gravitational field. Free fall reduces the effects of gravity (e.g. sedimentation) so that it appears that gravity has been reduced to zero. Drop towers create microgravity conditions for experiments by allowing the experiments to free fall for a short period of time. At NASA Glenn, the Microgravity Science Division utilizes two drop facilities, the 2.2 Second Drop Tower and the Zero-G Research Facility.

The 2.2 Second Drop Tower, Figure 1, operates daily with twelve 45-minute intervals, each of which is a complete experiment drop operation. Typically, experiments are prepared in an off-line laboratory and the 45 minutes available for the drop operation are used efficiently to conduct final experiment preparations, integration into a drag shield, the drop itself, and recovery of the experiment apparatus. The free-fall time in this facility is 2.2 seconds for the 24-meter drop, Figure 2.

The facility has utilized a general-purpose drop rig for many years to drop demonstration science "experiments" for visitors. The demonstration experiments include basic physics demonstration such as sedimentation, balance of forces, and thermal convection. These demonstration devices are described in an educators handbook for a small demonstration drop tower (ref. 2). for use with DIME, the general purpose drop rig was modified to be an Education Rig by creating a standard interface at which student experiment apparatus would be mounted and electrically connected.

\section{DIME COMPETITION FUNDAMENTALS}

The DIME program was created to allow high-schoolage student teams to develop a scientific hypothesis, conceive an experiment to test that hypothesis, write a proposal that describes the hypothesis and experiment. If a team is selected, then the team designs and builds the experiment apparatus to conduct their experiment in a NASA scientific research facility.

As described in the DIME program announcement (ref. 3), DIME allows the student teams to:

- develop an understanding of microgravity science through research,

- develop a hypothesis for some phenomena influenced by gravity, and

- write a scientific proposal for an experiment to test the hypothesis.

A team's scientific proposal is combined with other requisite forms into a DIME entry package which is submitted to NASA for evaluation and scoring.

The submitted entries are evaluated by a team of NASA and NCMR scientists and engineers according to the rubric published in the DIME competition announcement. Teams representing the top four 
proposals are selected as winners. The selected teams then proceed to:

- design their experiment,

- submit the design to NASA for review,

- test the experiment concept,

- improve the design based on test results and NASA comments,

- fabricate their experiment apparatus according to the design, Figure 3,

- develop procedures for operation of their experiment,

- conduct their experiment in the NASA 2.2 Second Drop Tower, Figures 4 and 5,

- modify the experiment apparatus, and/or procedures as required based on testing results,

- analyze their data,

- present preliminary results to the other teams, and

- write a final report on the results of their experiment and submit it to NASA.

These activities support education standards for scientific research.

\section{DIME SCHEDULE}

The DIME program has been designed to be a schoolyear activity for the selected teams as shown in Figure 6. Each student team preparing a proposal will learn about microgravity, develop a hypothesis, and write a proposal prior to the submission date in early November. The team may begin the proposal development process at their discretion, most likely at the beginning of the school year, but it is possible to begin during the preceding summer or even during the previous school year. The only critical date in this stage is the postmark date for submission of the proposal to NASA.

A description of the DIME program and the proposal entry rules are available on the internet from a DIME web page (ref. 4) and from a DIME CD-ROM. Both of these sources also provide microgravity resources and a description of the 2.2 Second Drop Tower.

A team of NASA and NCMR scientists and engineers evaluate the submitted proposals and announce the selected teams by mid-December. The selected teams may then start their experiment design, if they have not done so already.

A NASA or NCMR mentor is assigned to each team after the selection process has been completed. This scientist or engineer will assist their team with advice and encouragement during the design and construction phase. The mentor also serves as the team's facilitator with the drop tower facility staff during DIME Drop
Days. The mentor works directly with the team during DIME Drop Days to help ensure successful operation of the experiment.

The selected teams submit a preliminary design package and a final design package for NASA review and approval by the end of January and February, respectively. The design reviews allow NASA to offer guidance and advice to each team to help ensure the experiment will be successful. These reviews also provide NASA insight into the experiment designs to spot potential safety issues early.

At the beginning of April, each team ships their experiment apparatus to NASA for a review of safety features and overall workmanship.

Travel and per diem expenses for three days are provided by NASA for four student representatives and an adult advisor from each team to attend the DIME Drop Days at NASA Glenn in Cleveland, Ohio where they will conduct their experiment in the drop tower, participate in workshops, tour the NASA center, and participate in other fun activities.

After DIME Drop Days, each student team prepares a final report summarizing their scientific findings and conclusions as well as summarizing their DIME experience. These final reports are submitted to NASA by June 1 .

\section{EDUCATION STANDARDS}

The DIME program supports specific national standards in science and technology. Participation in DIME will contribute to student mastery of the standards in Table 1.

The students will accomplish a scientific inquiry process by investigating microgravity, developing a hypothesis and conceiving an experiment to test that hypothesis. The experiment apparatus design will need to be developed and built to rigorous safety and operational standards of the NASA drop tower.

\section{TEAM APPROACH}

A team approach is encouraged where team members with the requisite skills are included since there are a variety of tasks to be accomplished if a team expects to be successful. Science students study the phenomena of microgravity as a topic of physics and they research experiment concepts as topics of physical science. Skills in page layout and word processing are necessary due to the specific rules for preparing a proposal, including page layout format, number of pages, and technical 
content. Attention to detail is important in the final preparation of an entry to verify the proposal and associated forms meet the DIME rules. Technology students prepare the conceptual drawings in the proposal as well as the design drawings once the team is selected. The construction of the experiment apparatus can be done by or with technology students. Science students conduct $1 \mathrm{~g}$ ground tests with the experiment to prove out operations and to gather baseline experiment data with which to compare the data from microgravity tests.

Mentors are an important part of a team's work in DIME, including the adult team advisor and local scientists and engineers. The adult team advisor and a local mentor (if there is one) should guide the students, not do the work for the students.

\section{SELECTION PROCESS}

A selection process for evaluating and selecting the winning teams from the submitted proposals has been developed. The DIME rules state that the proposals are created in a 'blind' fashion in which no information about students' names or location is included in the technical portion of the proposal. All such information is contained on forms seen only by DIME staff, not evaluators. This process permits a fair evaluation of all proposals based on scientific merit with no bias for location or ethnic background of students, organization, or advisor.

Emphasis is placed on the science and engineering aspects of the proposal as seen in the breakdown of points in Table 2. A subsection of the rubric used for DIME is included as Table 3 . The entire rubric is included in the DIME Program Announcement to guide the teams while preparing their proposal. The evaluators use this rubric to score the proposals. The possible scores by section are included in the announcement.

\section{SELECTION OF WINNERS}

The evaluators' scores are presented to the DIME staff who then rank the proposals and select the winners. After selection, the advisor for each selected team is notified of their team's success. The team is soon rewarded with the shipment of a metal plate on which their experiment apparatus will be constructed.

At that time also, the advisor of each non-selected team is given regrets from the DIME staff as well as a summary of the evaluation results of their proposal. A participation certificate and NASA educational material are sent to each team.

\section{ALTERNATIVES FOR NON-SELECTED TEAMS}

For non-selected teams, the efforts put forth in microgravity study and scientific research to create a proposal may be used as the basis for science fair projects. With the team selection announcement in midDecember, there is sufficient time for students to expand their work into projects for spring science fairs. These teams may also use the opportunity to critically examine their proposal, their hypothesis, and the experiment concept. The remaining school year time may be spent honing the proposal as a DIME proposal entry the following year.

A small drop tower could be constructed by the school and used by students to create their own demonstration devices based on the research previously performed for a DIME entry (ref. 2).

\section{DESIGN AND FABRICATION OF EXPERIMENT APPARATUS}

Following their selection, a NASA or NCMR mentor is assigned to guide the team through the more difficult stage of design, fabrication, and testing.

NASA furnishes each selected team a base plate and electrical connectors (as required) which together form the interface with the Education Rig used in the drop tower. The teams begin to develop the design of their experiment in more detail and submit a preliminary design to NASA for review. This review is to assess the technical aspects of the experiment design for:

- proper interface with the NASA rig,

- adherence to safety requirements,

- acceptable operation in the drop tower, and

- assurance that each team is progressing (and not waiting for the last minute).

One month later, the teams submit their final design for review of safety requirements compliance and technical feasibility.

A team's experiment needs to fit within a 12 inch cube (including the NASA-provided base plate) and weigh less than 25 pounds. Electrical power (28 VDC and 12 VDC) is provided by the NASA drop tower experiment carrier as are control relay contacts for activation of experiments. The carrier also contains a data logger for capturing electronic data signals and a video camera to record visual data from an experiment.

When construction is completed, the experiment is shipped to NASA Glenn in a NASA-provided shipping container. A NASA safety committee inspects the experiment apparatus and its design package and any 
discrepancies will need to be addressed before the experiment is allowed to operate in the drop tower. Safety is a high priority in the drop tower and student experiments are naturally expected to meet the applicable safety standards, as are all other experiments.

\section{DIME DROP DAYS AT NASA GLENN}

NASA provides travel expenses for four students and an adult advisor to attend DIME Drop Days at NASA Glenn in Cleveland, Ohio. The primary objective is to operate the teams' experiments in the 2.2 Second Drop Tower while also participating in workshops and touring some of the major facilities of the NASA Glenn Research Center. One of the first activities after meeting the other teams is to tour the drop tower facility, witness the drop operations of an experiment, and check over their experiment apparatus since it was shipped to NASA.

The workshops feature problem solving and team building exercises for the students, both in their original teams and as 'mixed' teams. Training in NASAdeveloped image analysis software is also provided to assist the teams in interpreting their experiment video data, if required. The NASA or NCMR mentor also works with the team to operate the experiment, assist with procedures and data interpretation. Visits to NASA microgravity research laboratories are also provided to the DIME teams to see first-hand some of the research currently being conducted.

\section{OPERATION OF STUDENT EXPERIMENTS IN DROP TOWER}

The students are involved in each step of the operation of their experiment apparatus. After a short orientation to the Education Rig, which carries their experiment in the drop tower, the students install their experiment in the rig, adjust the camera and load their sample materials. The team's operational procedures are checked and tested in $1 \mathrm{~g}$ for proper sequence and timing with the experiment apparatus and the rig. The electronic data logger (if used) is programmed and its operation and data are tested.

The student team's apparatus is finally tested in a microgravity environment on their first drop operation test. The initial test evaluates whether the procedures are correct, the camera settings are adjusted properly, and the experiment apparatus performs as expected. The initial test may also yield valid data. Problems found at this time can be corrected before the drops on the following day. Difficulties experienced in the initial drops in the first three years of Drop Days have included premature ignition of a combustion sample (procedure problem) and a low electromagnet magnetic field strength (hardware problem). These initial tests take the students and their experiment apparatus through the sequence of steps involved in preparing, operating, and troubleshooting their experiment through the complete drop operation.

The teams' experiment operations in the drop tower are webcast over the internet for interested people to observe. The web address for the webcast is included on the DIME web page. (ref. 4)

\section{STUDENT EXPERIMENTS FOR FIRST THREE YEARS}

The initial year for DIME occurred during the 2000/ 01 school year with two teams participating. One experiment studied the progression of a flame across a cotton cloth sample as a study in space station fire safety for crew members. The other experiment studied the effect of microgravity on the gravity-driven motion of soybeans in a carbonated beverage, where bubbles nucleating on the soybeans lift them in normal gravity, then burst at the surface allowing the beans to sink.

The second pilot year for DIME occurred during the $2001 / 02$ school year with four teams participating. There was one combustion experiment and three fluid physics experiments. The combustion experiment studied the flame spread across standard office paper in microgravity. One fluid physics experiment studied the interface shape between different combinations of oils and water in a microgravity environment. Another fluid physics experiment studied the effect of microgravity on the shape of a magnetic fluid immersed in alcohol within a magnetic field. A third fluid physics experiment studied the effect of microgravity and gravity on the shape and motion of immiscible fluid droplets.

The third year for DIME occurred during the 2002/03 school year with four selected teams. There was one magnetic field experiment and three fluid physics experiments. The magnetic field experiment used the interaction of several magnets in different orientations to investigate whether microgravity has an effect on magnetic strength. One fluid physics experiment investigated buoyancy of corks in water with corks being released under water after the initiation of the drop. Another fluid physics experiment studied crystallization of super cooled water. A third fluid physics experiments 
studied the sonoluminescence effect of ultrasonic waves on an air bubble.

\section{SUMMARY}

The student team members and the advisors enjoyed the DIME program and felt that they experienced a process similar to NASA research. The DIME teams participated in a process where they created a hypothesis, developed an experiment concept to test that hypothesis, and wrote a proposal to accomplish that research. As opposed to standard high school laboratory experiments, in DIME the students had to design and build their experiment apparatus and develop procedures for conducting the tests.

Performing the tests in the NASA 2.2 Second Drop Tower and analyzing the data with NASA mentors was a high point of their research. The DIME teams concluded their DIME research with a final report.

\section{REFERENCES}

1) Statement of Sean O'Keefe, Administrator, National Aeronautics and Space Administration before the Subcommittee on Science, Technology, and Space Committee on Commerce, Science, and Transportation, United States Senate, June 19, 2002

2) NASA (1998), The Microgravity Demonstrator, EG1998-12-49-MSFC, NASA Marshall Space Flight Center, Huntsville, AL

3) DIME Program Announcement, NASA Glenn Research Center,

http://microgravity.grc.nasa.gov/ MSD/DIME/DIME2003_PA.pdf

4) DIME web page,

http://microgravity.grc.nasa.gov/ DIME.html 
Table 1: National education standards which apply to DIME

National Science Teachers Association
(NSTA) Standards

Science as inquiry

+ Abilities necessary to do scientific inquiry

Science and technology

+ Abilities of technological design

International Technology Education Association (ITEA) Standards

Design

+ Students will develop an understanding of the attributes of design

Table 2: Possible points for major sections of DIME proposals

\begin{tabular}{|l|c|}
\hline \multicolumn{1}{|c|}{ Section } & Points \\
\hline \hline I. Science Objectives & 41 \\
\hline II. Technical Plan & 30 \\
\hline III. Team Organization & 9 \\
\hline $\begin{array}{l}\text { IV. Creativity, Originality, } \\
\text { Attention To Detail }\end{array}$ & 12 \\
\hline V. Resource Credits & 8 \\
\hline Total & 100 \\
\hline
\end{tabular}


Table 3: One subsection of the DIME rubric for proposal evaluation

\begin{tabular}{|c|c|c|c|c|}
\hline \multicolumn{5}{|c|}{ I. SCIENCE OBJECTIVES } \\
\hline \multicolumn{5}{|c|}{ (A) RESEARCH QUESTION / HYPOTHESIS } \\
\hline POINTS & $\begin{array}{l}\text { 1. Does the proposal } \\
\text { have a clear research } \\
\text { question and } \\
\text { hypothesis? }\end{array}$ & $\begin{array}{l}\text { 2. Does the proposal } \\
\text { have a hypothesis } \\
\text { related to the } \\
\text { research question? }\end{array}$ & $\begin{array}{l}\text { 3. Is microgravity a } \\
\text { major factor in this } \\
\text { proposed } \\
\text { experiment? }\end{array}$ & $\begin{array}{l}\text { 4. Is the hypothesis } \\
\text { testable in } 2.2 \\
\text { seconds? }\end{array}$ \\
\hline 1 & $\begin{array}{l}\text { Neither research question } \\
\text { nor hypothesis are } \\
\text { presented in the proposal. }\end{array}$ & $\begin{array}{l}\text { The relationship of the } \\
\text { hypothesis and the } \\
\text { research question cannot } \\
\text { be determined. }\end{array}$ & $\begin{array}{l}\text { No clear connection to } \\
\text { microgravity is } \\
\text { explained. }\end{array}$ & $\begin{array}{l}\text { Unable to detect factors } \\
\text { in experiment to } \\
\text { determine response time. }\end{array}$ \\
\hline 2 & $\begin{array}{l}\text { An unclear research } \\
\text { question or hypothesis is } \\
\text { stated. }\end{array}$ & $\begin{array}{l}\text { The hypothesis is } \\
\text { unclear; the experiment } \\
\text { relates poorly or not at all } \\
\text { to the research question. }\end{array}$ & $\begin{array}{l}\text { The need for } \\
\text { microgravity effect is } \\
\text { unclear or was not } \\
\text { explained clearly. }\end{array}$ & $\begin{array}{l}\text { The information is } \\
\text { unclear or not stated; the } \\
\text { experiment samples may } \\
\text { need to be modified. }\end{array}$ \\
\hline 3 & $\begin{array}{l}\text { A research question and } \\
\text { hypothesis are present } \\
\text { but both are poorly } \\
\text { stated, or may contain } \\
\text { inaccuracies. }\end{array}$ & $\begin{array}{l}\text { The hypothesis is clear } \\
\text { and is somewhat related } \\
\text { to the research question. }\end{array}$ & $\begin{array}{l}\text { A microgravity effect is } \\
\text { clear and somewhat } \\
\text { utilized in the } \\
\text { experiment. }\end{array}$ & $\begin{array}{l}\text { Response time short } \\
\text { enough for reaction to be } \\
\text { complete within } 2.2 \\
\text { seconds. }\end{array}$ \\
\hline 4 & $\begin{array}{l}\text { A clear research question } \\
\text { and hypothesis are } \\
\text { present but they are not } \\
\text { testable, variables are not } \\
\text { identified, or they contain } \\
\text { inaccuracies. }\end{array}$ & $\begin{array}{l}\text { The hypothesis is clearly } \\
\text { stated and it appears that } \\
\text { the experiment will yield } \\
\text { significant data related to } \\
\text { the research question. }\end{array}$ & $\begin{array}{l}\text { The microgravity effect } \\
\text { is clearly stated and is } \\
\text { utilized in the } \\
\text { experiment. }\end{array}$ & $\begin{array}{l}\text { N/A } \\
\text { (item } 4 \text { is only } \\
\text { worth } 3 \text { points) }\end{array}$ \\
\hline 5 & $\begin{array}{l}\text { The research question is } \\
\text { clear, the hypothesis is } \\
\text { testable, variables are } \\
\text { identified; variables are } \\
\text { identified as dependent, } \\
\text { independent, and control } \\
\text { is defined. }\end{array}$ & $\begin{array}{l}\text { The hypothesis is clearly } \\
\text { stated and the experiment } \\
\text { will yield data that } \\
\text { address research question } \\
\text { and hypothesis in a } \\
\text { compelling way. }\end{array}$ & $\begin{array}{l}\text { Microgravity is essential } \\
\text { to the hypothesis and the } \\
\text { research question and is } \\
\text { described in detail. }\end{array}$ & N/A \\
\hline
\end{tabular}




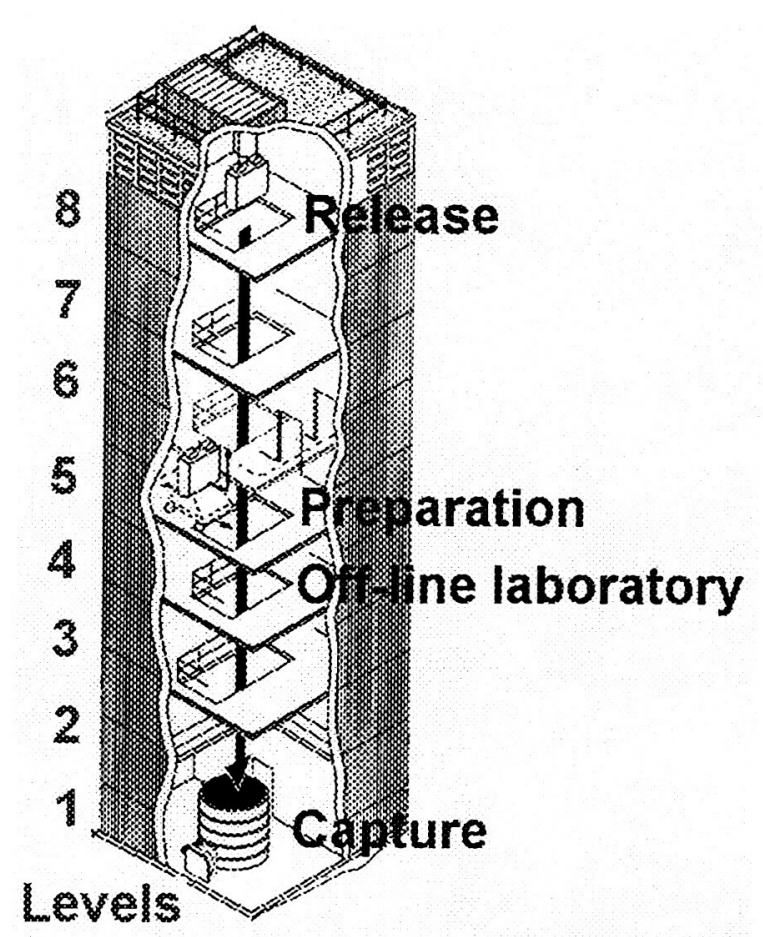

Figure 1: Diagram of the 2.2 Second Drop Tower.

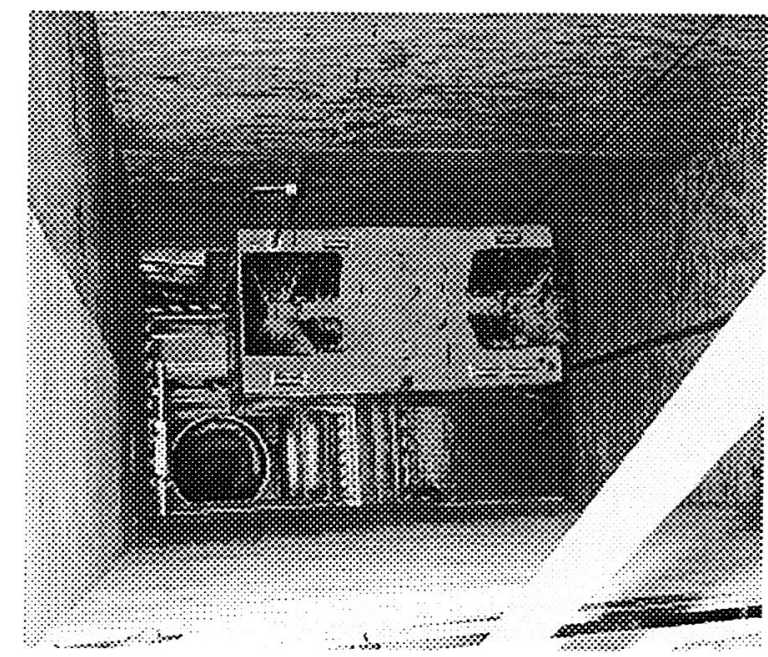

Figure 2: Drag shield and experiment (inside) midway through the 2.2 second free-fall.

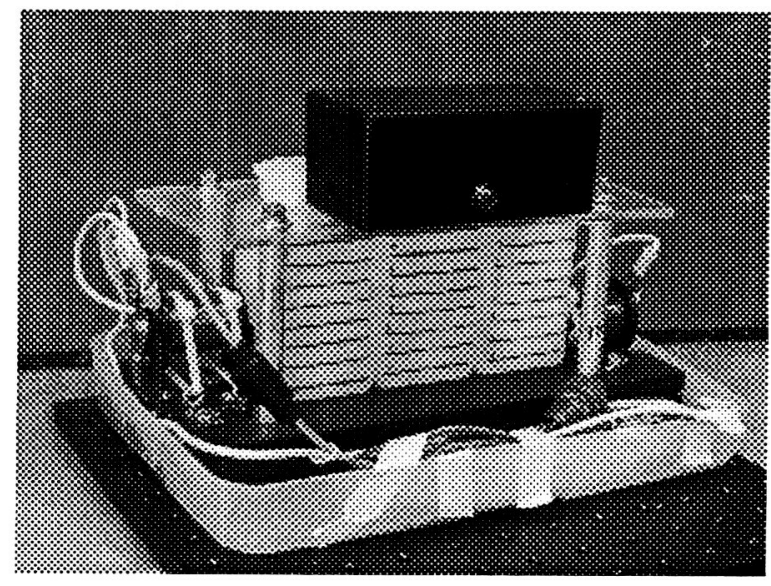

Figure 3: Three-chamber buoyancy experiment apparatus built by a student team for the DIME competition. The student's equipment is mounted to the NASA-provided black optical plate.

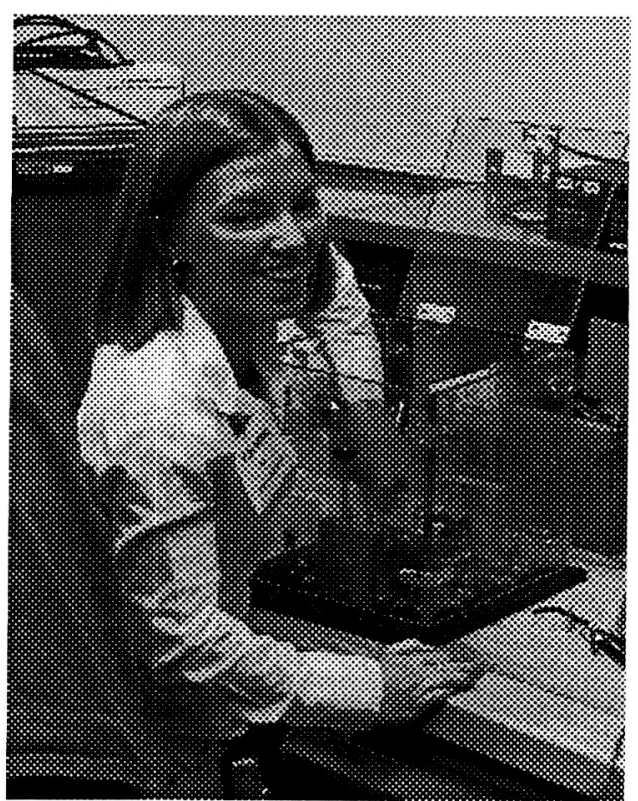

Figure 4: Student team member preparing samples in the experiment apparatus in an off-line laboratory. 


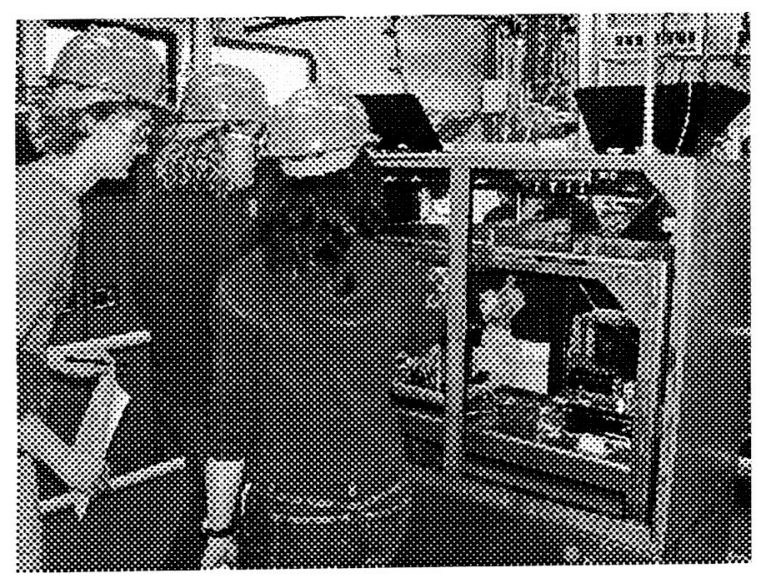

Figure 5: Student team members load corks in their experiment apparatus installed in the NASA drop rig.

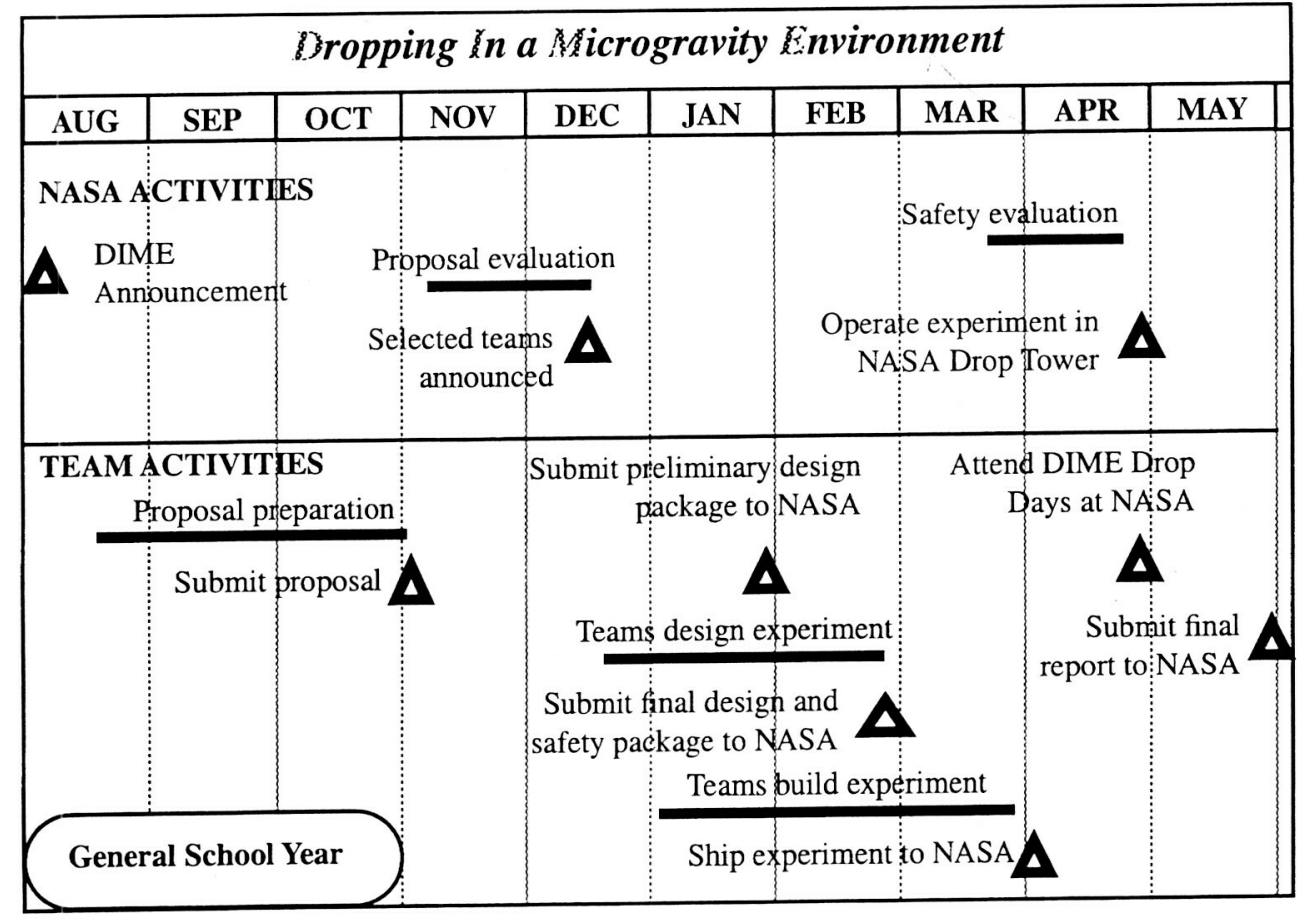

Figure 6: DIME school year schedule 